\section{Cysteine-Mediated Reductive Dissolution of Poorly Crystalline Iron(III) Oxides by Geobacter sulfurreducens}

\author{
RUEY-AN DOONG*AND
}

BERNHARD SCHINK ${ }^{\dagger}$

Department of Nuclear Science, National Tsing Hua University, Hsinchu, 30013, Taiwan, and Fakultät für Biologie, Universität Konstanz, Postfach 5560,

78457, Konstanz, Germany

The reductive dissolution of poorly crystalline ferric oxides in the presence of cysteine was investigated to evaluate the potential of cysteine as a possible electron carrier to stimulate the reduction of iron(III) oxides by Geobacter sulfurreducens. The extent and rate of biotic and abiotic reduction of iron(III) oxides in the presence of cysteine at various concentrations were compared. Iron(III) oxides were reduced abiotically by cysteine. The initial rate and extent of iron(III) oxide reduction were correlated linearly with the cysteine concentration ranging from 0 to $6 \mathrm{mM}$. Also, addition of $0.5-2 \mathrm{mM}$ cysteine significantly stimulated the rate and the extent of iron(III) oxide reduction in cultures of $G$. sulfurreducens. The cysteine concentration decreased in accordance with the increase of Fe(II) concentration and reached a nearly constant residual concentration. Cysteine depletion followed first-order kinetics and increased linearly with the cysteine concentration. An 8- to 11-fold increase in the extent of iron(III) oxide reduction relative to the abiotic system was observed. Comparison of sorbed and dissolved Fe(II) concentrations between cultures amended with cysteine and with other organic chelators showed that solubilization is not the main factor in cysteine-stimulated $\mathrm{Fe}(\mathrm{III})$ reduction. Addition of cystine could enhanced the extent of iron(III) oxide reduction, concomitant with the increase of the regenerated cysteine concentration and support the hypothesis that cysteine could serve as an electron carrier to transfer electrons from $G$. sulfurreduc ens to poorly crystalline iron(III) oxides.

\section{Introduction}

Iron is one of the most important essential elements in living cells and in the environment. The biogeochemical cycle of iron is intimately linked with those of carbon and sulfur and is a primary path in energy flux under anoxic conditions as prevailing in certain soils and sediments $(1,2)$. In many natural environments, oxygen supply is limited, but Fe(III) is present as an alternative oxidant mostly in the form of crystallineminerals. Thirteen iron oxides, oxyhydroxides, and

* Corresponding author phone: +886-3-5726785; fax: +886-35718649; e-mail: radoong@mx.nthu.edu.tw. Mailing address: 101 Sec. 2, Kuang Fu Road, Department of Nuclear Science, National Tsing Hua University, Hsinchu, 30013, Taiwan.

+ Universität Konstanz.

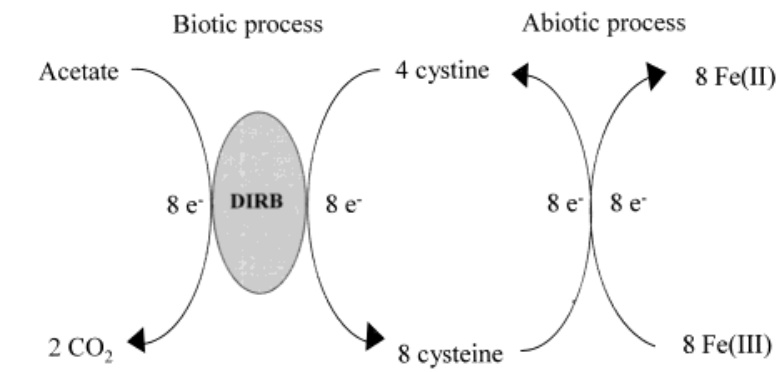

FIGURE 1. Schematic mechanism for biotic and abiotic processes involved in cysteine-iron(III) oxide reduction.

hydroxides are known to exist in the environment. Although crystalline forms of iron(III) oxides such as goethite and hematite are typically the most abundant iron minerals, poorly crystalline iron(III) oxide (ferrihydrite) may be more important for microbial reduction due to its large specific surface area and high susceptibility to dissolution (3).

Iron(III) oxides can be reductively dissolved by abiotic and biotic processes. The abiotic reduction of iron(III) oxides has been studied with several different reductants, complexing agents, and iron oxides (4-7). Hydrogen sulfide and ascorbic acid wereshown to beeffectivereductants of iron(III) oxides. Also, microbial iron(III) oxide reduction plays an important rolein the reductive dissolution of iron(III) oxides. Several dissimilatory iron-reducing bacteria (DIRB) such as Shewanella alga and Geobacter metallireducens have been studied extensively (8-11). Factors including crystallinity, particlesize, specific surface area, and identity of theiron(III) oxides (12-14) as well as the presence of chelating agents $(15,16)$ have been shown to influence the rate of iron(III) oxide reduction. The discovery of iron(III) oxide reduction by humic acids (17) and extracellular quinones (18) encourages the search for possible electron shuttling compounds that are excreted by microorganisms for efficient dissimilatory iron(III) reduction. Current evidence suggests that compounds carrying quinone moieties, such as humic acids or anthraquinone-2,6-disulfonate (AQDS), can effectively stimulate the dissolution of iron(III) oxides in the presence of $\mathrm{Fe}(\mathrm{III})$-reducing bacteria(18-20). So far, no other compounds were reported to serve as electron shuttles for Fe(III) reduction.

Cysteine $\left(\mathrm{HSCH}_{2} \mathrm{CHNH}_{2} \mathrm{COOH}\right)$ is an essential amino acid for many living cells and can befound especially in electrontransfer proteins such as heme proteins, ferredoxins, and rubredoxins. Interactions between cysteine and dissolved $\mathrm{Fe}(\mathrm{III})$ and $\mathrm{Fe}(\mathrm{II})$ have been addressed in several studies (21, 22). Cysteine was al so reported to abiotically reduce iron(III) oxides (23). The overall reaction between cysteineand Fe(III) is a one-electron-transfer process that involves thethiol group and results in the reduction of $\mathrm{Fe}(\mathrm{III})$ to $\mathrm{Fe}(\mathrm{II})$ and the oxidation of cysteine to cystine. The interaction of Fe and thiol groups is common also iron-sulfur proteins in which cysteine acts as the protein ligand binding the Fe center. Recently, the utilization of cysteine as an electron carrier in interspecies electron transfer between Geobacter sulfurre ducens and Wolinella succinogenes was reported (24). This implies that cysteine may also transfer electrons from Fe(III)reducing bacteria to iron(III) oxides (Figure 1).

The objective of the present study was to evaluate the potential of cysteine as possible electron carrier to stimulate the reduction of poorly crystalline ferric oxide. The extent and rate of abiotic and biotic reductions of iron(III) oxides in the presence of cysteine at various concentrations were 
compared. The results demonstrated that both cysteine and cystine can increase the rate and extent of iron(III) oxide reduction by $\mathrm{G}$. sulfurreducens and support the hypothesis that cysteine could act as an electron carrier to transfer electrons from G. sulfurreducens to iron(III) oxides.

\section{Materials and Methods}

Organismsand Cultivation. G. sulfurreducenswas obtained from Dr. D. Lovley, Amherst, MA. Purity was checked by microscopy at regular intervals. Strictly anaerobic techniques were employed throughout as previously described (25). Bacteria were grown in bicarbonate-buffered mineral media at $\mathrm{pH} 7.1 \pm 0.1$. Thecompositions of medium used for growth and iron reduction experiments were (in $\mathrm{mM}) \mathrm{NH}_{4} \mathrm{Cl}$ (4.7), $\mathrm{KCl}$ (6.7), $\mathrm{KH}_{2} \mathrm{PO}_{4}$ (1.4), $\mathrm{NaCl}$ (17.1), $\mathrm{MgCl}_{2} \cdot 6 \mathrm{H}_{2} \mathrm{O}$ (2.0), and $\mathrm{CaCl}_{2} \cdot 2 \mathrm{H}_{2} \mathrm{O}$ (1.0). After autoclaving and cooling under an atmosphere of $\mathrm{N}_{2} / \mathrm{CO}_{2}(80 / 20, \mathrm{v} / \mathrm{v}), 30 \mathrm{mM}$ sodium bicarbonate as buffer solution, $1 \mathrm{~mL}$ of trace element solution, and selenite-tungstate solution were added per liter. No reducing agent or vitamin solution was added to the anoxic solution in order to avoid the introduction of potential electron shuttling compounds. Acetate $(20 \mathrm{mM})$ and fumarate $(40 \mathrm{mM})$ were added as the electron donor and electron acceptor, respectively. All cultures were incubated at $28^{\circ} \mathrm{C}$ in the dark.

Synthesis and Characteristics of Ferrihydrite. Ferrihydrite was synthesized by neutralizing $0.4 \mathrm{M}$ ferric chloride with $1 \mathrm{M} \mathrm{NaOH}$ according to the procedures of Lovley and Phillips (26). The precipitate was washed 4 times with bidistilled water to removedissolved ions. Theresulting ferric iron suspension was degassed and gassed with $\mathrm{N}_{2}$ gas several times and maintained under $\mathrm{N}_{2}$ atmosphere in tightly sealed serum bottles. The ferric iron suspension was autoclaved afterward and stored at room temperature under anoxic conditions. The measured specific surface area of the prepared iron(III) oxides, as determined by BET $\mathrm{N}_{2}$ adsorption analyzer (Micromeritics ASAP 2000), was $342 \mathrm{~m}^{2} / \mathrm{g}$.

Reductive Dissolution of Ferrihydrite. To elucidate the relationship between abiotic and biotic reduction of ferrihydrite by cysteine, biotic and abiotic experiments were conducted simultaneously under anoxic conditions. For abiotic experiments, the $30 \mathrm{mM}$ bicarbonate-buffered medium containing $10 \mathrm{mM}$ iron(III) oxide was amended with various concentrations of cysteine ranging from 0 to $6 \mathrm{mM}$. For biotic experiments, G. sulfurreducenswas inoculated into the bicarbonate-buffered medium with $10 \mathrm{mM}$ acetate as an electron donor. The initial $\mathrm{pH}$ value of the medium was at $7.1 \pm 0.1$ and was maintained between 6.9 and 7.3 throughout the study. The cysteine concentration in these experiments was $0.5-2 \mathrm{mM}$. All batches were run in duplicate or triplicate and incubated on a shaker at $125 \mathrm{rpm}$ and at $28^{\circ} \mathrm{C}$ in the dark.

Kinetics of Fe(II) Sorption on Ferrihydrite. The sorption of $\mathrm{Fe}(\mathrm{II})$ onto ferrihydrite was examined under anoxic conditions at various concentrations of Fe(II) $(0-10 \mathrm{mM})$ in the presence of $10 \mathrm{mM}$ iron(III) oxides. All samples were incubated on a shaker at $125 \mathrm{rpm}$ and at $28^{\circ} \mathrm{C}$ and were allowed to equilibrate for $6 \mathrm{~h}$. After reaching equilibrium, the supernatants were filtered through $0.2 \mu \mathrm{m}$ cellulose acetate filters and were acidified with $1 \mathrm{~N} \mathrm{HCl}$. The aqueous $\mathrm{Fe}(\mathrm{II})$ concentration was measured using the ferrozine assay (27). Sorbed Fe(II) was calculated from the difference between the total and the dissolved aqueous Fe(II) concentrations.

Analytical Procedures. Concentrations of total $\mathrm{HCl}$ extractable $\mathrm{Fe}(\mathrm{II})$ in the cultures were monitored in $0.5 \mathrm{~mL}$ samples drawn with $\mathrm{N}_{2} / \mathrm{CO}_{2}(80 / 20, \mathrm{v} / \mathrm{v})$ purged syringes which wereimmediately acidified with $1 \mathrm{~N} \mathrm{HCl}$. Theacidified samples were centrifuged at $14000 \mathrm{~g}$ for $10 \mathrm{~min}$ to remove particles, and the $\mathrm{Fe}(\mathrm{II})$ contents were determined with ferrozine at $562 \mathrm{~nm}(26,27)$. The dissolved fraction of Fe(II) was determined in filtrates $(0.2-\mu \mathrm{m}$ cellulose acetate filter) acidified with $0.5 \mathrm{~mL}$ of $1 \mathrm{~N} \mathrm{HCl}$. A previous study (11) compared the soluble Fe(II) measured after using different pore sizes of filters and found no difference in soluble Fe(II) concentrations after passing through $0.2 \mu \mathrm{m}$ and $1.8 \mathrm{~nm}$ filters, demonstrating that the $0.2 \mu \mathrm{m}$ filter was sufficient to filter Fe(II) solids.

Acetateconcentrationsweremeasured by HPLC (28). One milliliter samples were withdrawn from serum bottles and were centrifuged at $14000 \mathrm{~g}$ for $10 \mathrm{~min}$. Samples of supernatant $(0.3 \mathrm{~mL})$ were acidified with $60 \mu \mathrm{L}$ of $300 \mathrm{mM}$ sulfuric acid, and acetate in the supernatants was analyzed by HPLC on a Bio-Rad Aminex HPX-87H column $(300 \times 7.8 \mathrm{~mm})$ with an ERC-7512 refraction index detector (Erma) with $5 \mathrm{mM}$ $\mathrm{H}_{2} \mathrm{SO}_{4}$ as the eluent.

Cysteine was determined using 5,5'-dithiobis(2-nitrobenzoic acid) (DTNB) (also called Ellman's reagent), a sulfhydryl group determining reagent (29). Samples $(0.5 \mathrm{~mL})$ were withdrawn with $\mathrm{N}_{2} / \mathrm{CO}_{2}$ purged syringes and centrifuged for $5 \mathrm{~min}$ at $14000 \mathrm{~g}$ to remove particles. Supernatants $(0.1 \mathrm{~mL})$ were mixed with $1 \mathrm{mM}$ DTNB in a $50 \mathrm{mM}$ phosphate buffer, $\mathrm{pH}$ 8.0. The cysteine concentration was monitored with a spectrophotometer at $412 \mathrm{~nm}\left(\epsilon=14100 \mathrm{M}^{-1} \mathrm{~cm}^{-1}\right)$. The relative standard deviation (RSD) was within $5 \%$, and the detection limit was $5.7 \mu \mathrm{M}$.

\section{Results and Discussion}

Abiotic Reduction of I ron(III) Oxideswith Cysteine. Cysteine containsathiol group and can abiotically reducechlorinated compounds and iron(III) oxides under anoxic conditions (23, 30). Therefore, the nonenzymatic reduction of ferrihydrite by cysteinewasstudied first to elucidatethebiotic and abiotic effects of cysteine on Fe(III) reduction.

No reduction of ferrihydrite was observed in the absence of cysteine. Addition of cysteine stimulated the abiotic reduction of ferrihydrite, and the rate and extent of iron(III) oxide reduction increased with increasing cysteine concentrations (Figure 2A). The final Fe(II) concentration reached increased from $0.20 \mathrm{mM}$ at $0.5 \mathrm{mM}$ cysteine to $2.84 \mathrm{mM}$ at $6 \mathrm{mM}$ cysteine within 15 days.

The bulk Fe(II) production can be described by a firstorder rate equation in which Fe(III) reduction depends on the concentration of free iron(III) oxide surface reduction sites (10)

$$
\begin{gathered}
\frac{d F e(I I)}{d t}=k_{o b s} F e(I I I) \\
F e(I I)_{t}=F e(I I I)^{0}\left(1-\exp \left(-k_{o b s} t\right)\right)
\end{gathered}
$$

where $\mathrm{Fe}(\mathrm{II})_{\mathrm{t}}$ is the concentration of $\mathrm{Fe}(\mathrm{II})$ at time $\mathrm{t}, \mathrm{Fe}(\mathrm{III})^{0}$ is the initial concentration of ferrihydrite, and $\mathrm{k}_{\text {obs }}$ is the firstorder rate constant. The first-order rate constant $\left(k_{o b s}\right)$ increased linearly from 0.0012 day $^{-1}$ at $0.5 \mathrm{mM}$ cysteine to 0.0039 day $^{-1}$ at $2 \mathrm{mM}$ cysteine and leveled off to 0.0072 day $^{-1}$ when $6 \mathrm{mM}$ cysteine was applied (Figure 2B). Because the reduction of ferrihydrite is supposed to bea surface-mediated reaction, a Langmuir-Hinshelwood kinetic formulation was used to describetherelationship between theinitial cysteine concentration and the reaction rate

$$
\Gamma=k_{r x n} \frac{K_{\text {cys }} C_{c y s}}{1+K_{c y s} C_{c y s}}
$$

where $\Gamma$ is the reaction rate, $\mathrm{k}_{\mathrm{rxn}}$ is the apparent reaction rate constant, $K_{\text {cys }}$ is the equilibrium constant for cysteine, and $\mathrm{C}_{\text {cys }}$ is the aqueous initial concentration of cysteine. A good fit between the initial cysteine concentration and the firstorder rate constant was obtained $\left(r^{2}=0.994, n=7\right)$, 

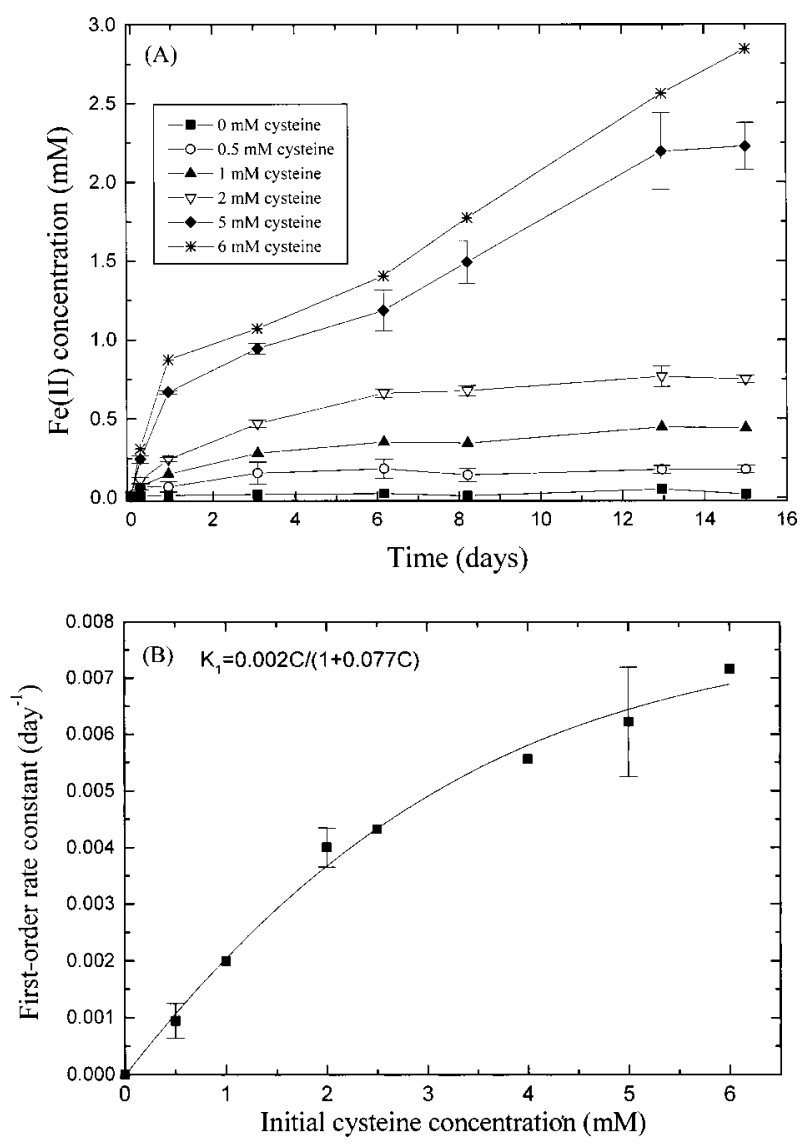

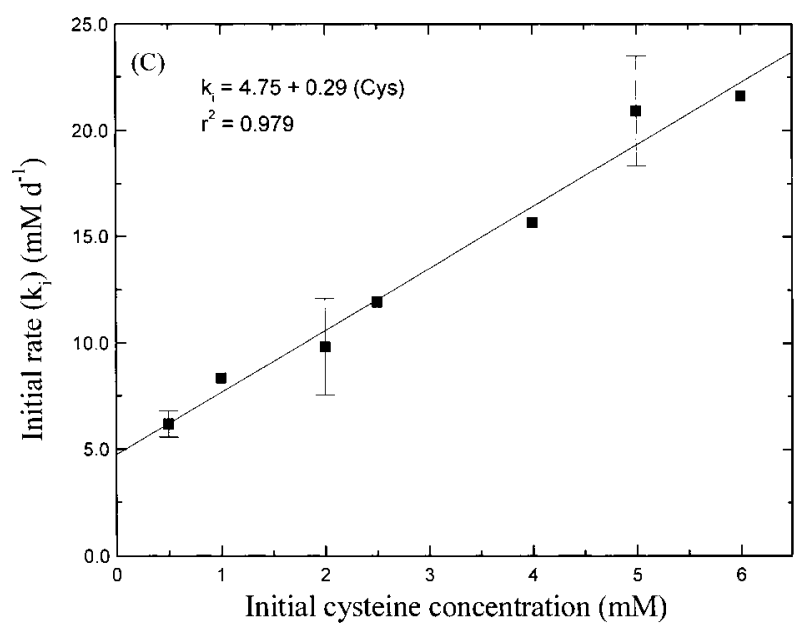

Initial cysteine concentration $(\mathrm{mM})$

FIGURE 2. Abiotic reduction of $10 \mathrm{mM}$ poorly crystalline iron(III) oxides with various initial cysteine concentrations in $30 \mathrm{mM}$ bicarbonatebuffered solution. The initial $\mathrm{pH}$ value was at $7.1 \pm 0.1$. (A) Fe(II) production, (B) first-order rate constant, and (C) initial rate as a function of initial cysteine concentration.

illustrating that a limited number of activesites on thesurface of ferrihydrite is available for reduction by cysteine. The limitation of active sites at high concentrations of cysteine may be due to sorption of ferrous iron onto the surface of ferric oxides. Previous studies with goethite and Shewanella alga have shown that ferrous iron can sorb onto the surface of iron(III) oxide and subsequently decrease the rate of iron(III) oxide reduction $(11,14)$. We observed that the total Fe(II) concentration in the cysteine-amended reaction mixture increased within $0.5 \mathrm{~h}$ and then decreased with time in $2 \mathrm{~h}$. If the initial rate $\left(\mathrm{k}_{\mathrm{i}}\right)$ within $0.5 \mathrm{~h}$ was used, a linear correlation between $\mathrm{k}_{\mathrm{i}}$ and the cysteine concentration was observed $\left(r^{2}=0.96, n=7\right.$ ) (Figure $\left.2 C\right)$, reflecting that the produced ferrousion could block activesorption sites on the surface of ferrihydrite.

Approximately $2-28 \%$ of ferrihydrite was abiotically reduced to $\mathrm{Fe}(\mathrm{II})$ by cysteine at different concentrations. However, a nearly constant efficiency of ferrihydrite conversion (40-50\%) was obtained when normalized to the cysteine concentration. Becausethe overall reaction between cysteine and iron(III) oxides is a one-electron-transfer process, a 1:1 correspondence between the cysteine and Fe(II) can be expected. The limited efficiency of $\mathrm{Fe}(\mathrm{III})$ reduction by cysteine may beattributed to the existence of other oxidants. Cysteine was recovered to $98.1 \pm 9.4 \%(n=10)$ after 10 days if the mixture did not contain ferrihydrite. This proves that the incubation bottles used in this study were oxygen-free and did not contain any other oxidant. Sorption of cysteine on iron(III) oxides is another plausible reason for theobserved low reduction efficiency. A previous study showed that cysteine could sorb to ferrihydrite as a function of $\mathrm{pH}$ and that the maximum sorption capacity was found at $\mathrm{pH} 7.3$ (23). A linear correlation between the depletion of cysteine and the produced Fe(II) concentration was also established in our study, indicating that sorption of cysteine onto ferrihydrite impaired the efficiency of ferrihydrite reduction.

Microbial Reduction of Iron(III) Oxides with Cysteine. In bicarbonate buffer in the absence of cysteine, G. sulfurreducens stimulated the reduction of synthetic poorly crystalline iron(III) oxide only slightly (Figure $3 A$ ). Approximately $4-6 \%$ of the total iron(III) oxides was reduced to $\mathrm{Fe}(\mathrm{II})$ in the reaction mixture containing $10 \mathrm{mM}$ acetate as an electron donor. Addition of cysteine enhanced both the rate and the extent of Fe(III) reduction significantly. The $\mathrm{Fe}(\mathrm{II})$ concentration after 22 days of incubation increased from $2.69 \mathrm{mM}$ in the cultures containing $0.5 \mathrm{mM}$ cysteine to $6.73 \mathrm{mM}$ with $2 \mathrm{mM}$ cysteine. Also, the initial rate of Fe(II) production increased linearly from $0.003 \mathrm{mM}$ day ${ }^{-1}$ without cysteine to $0.869 \mathrm{mM}$ day $^{-1}$ with $2 \mathrm{mM}$ cysteine $\left(r^{2}=0.994\right)$ (Figure 3B), showing that addition of cysteine enhances the rate of microbial iron(III) oxide reduction.

The concentration of cysteine decreased in accordance with theincrease of Fe(II) concentration and reached a nearly constant residual concentration after $42 \mathrm{~h}$. The depletion of cysteine followed a first-order reaction kinetics (Figure 4). The first-order rate constant $\left(\mathrm{k}_{1}\right)$ increased linearly from $0.0089 \mathrm{~h}^{-1}$ at $0.5 \mathrm{mM}$ cysteineto $0.0351 \mathrm{~h}^{-1}$ at $2 \mathrm{mM}$ cysteine. Also, the initial rate of cysteine depletion at different concentrations was nearly constant $\left(0.211-0.228 \mathrm{mM} \mathrm{h}^{-1}\right.$ ) (Table 1). This value is similar to that observed in the abiotic system amended with $2 \mathrm{mM}$ cysteine $\left(0.251 \mathrm{mM} \mathrm{h}^{-1}\right)$, depicting that the initial depletion of cysteine is mainly attributed to the nonenzymatic process. Note that the depletion patterns of $2 \mathrm{mM}$ cysteine in the biotic and the abiotic reactions were different. A 3-fold increase in $\mathrm{k}_{1}$ relative to the abiotic system was observed in the biotic system. A 

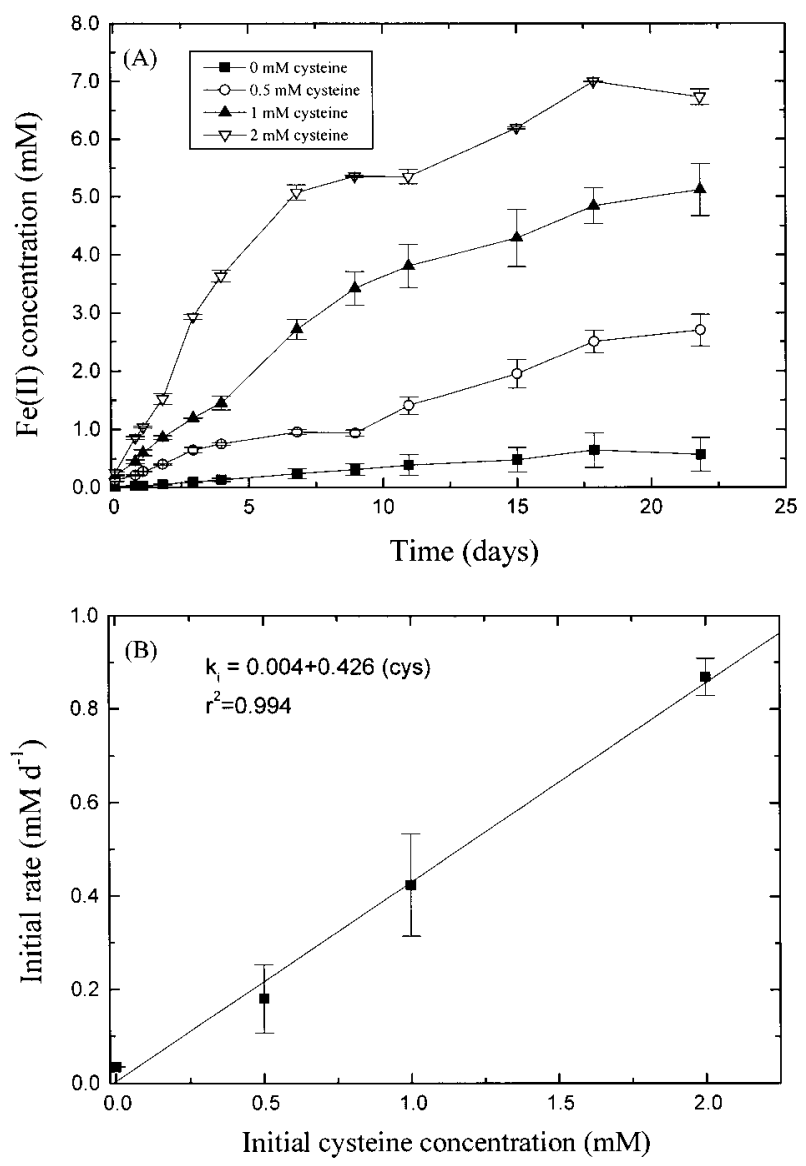

FIGURE 3. Microbial reduction of $10 \mathrm{mM}$ poorly crystalline iron(III) oxides by $G$. sulfurreducens amended with various initial cysteine concentrations in $30 \mathrm{mM}$ bicarbonate-buffered media. The initial $\mathrm{pH}$ value $w$ as at $7.1 \pm 0.1$. (A) Fe(II) production and (B) initial rate as a function of initial cysteine concentration.

recent study (24) showed that a low cysteine concentration (0.1 mM) was sufficient to stimulate the growth of $\mathrm{G}$. sulfurreducens coupled with the oxidation of acetate. This means that the high cysteine depletion in biotic system is probably due to partial assimilation of cysteine by $\mathrm{G}$. sulfurreducens.

The consumption of acetate increased slightly from 1.05 $\mathrm{mM}$ in the absence of cysteine to $1.67 \mathrm{mM}$ in the culture amended with $2 \mathrm{mM}$ cysteine (Table 1). The increase in acetate consumption in the presence of cysteine is also in accordance with the production of $\mathrm{Fe}(\mathrm{II})$ concentrations. Because acetate can serve as a carbon source for $\mathrm{G}$. sulfurreducens to produce new cell mass via the TCA cycle (28), depletion of acetate in the absence of cysteine may partly be due to its utilization by G. sulfurreducens as carbon source. G. sulfurreducens can also use acetate as electron donor to producestoichiometrically eight electrons for Fe(III) reduction (31). A total of 66.7-109\% of electrons from acetate were recovered as $\mathrm{Fe}(\mathrm{II})$ in the presence of cysteine, supporting the result that cysteine enhanced the reductive dissolution of ferrihydrite effectively.

The mass of the inorganic solids decreased in the experiment amended with $0.5 \mathrm{mM}$ cysteine (Table 1). This decrease was probably due to the dissolution of iron(III) oxides. The produced Fe(II) increased from $0.37 \mathrm{mM}$ without addition of cysteine to $2.69 \mathrm{mM}$ with $0.5 \mathrm{mM}$ cysteine, which corresponds to $248 \mathrm{mg} / \mathrm{L}$ of $\mathrm{Fe}(\mathrm{OH})_{3}$ loss. This value is close to the difference of suspended solids between these two reaction sets ( $253 \mathrm{mg}$ of $\mathrm{SS} / \mathrm{L}$ ). U nlike the sets containing 0.5 $\mathrm{mM}$ cysteine, the total suspended solids increased at high

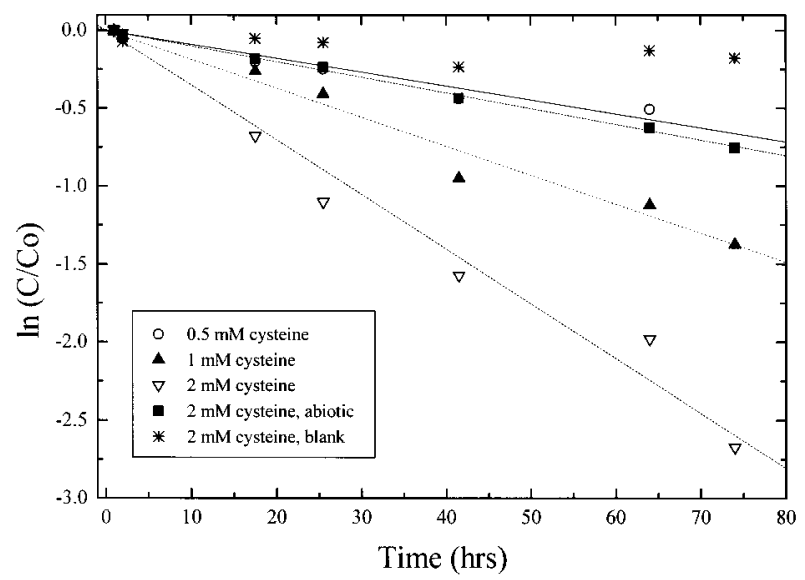

FIGURE 4. Cysteine concentration in $30 \mathrm{mM}$ bicarbonate-buffered cultures inoculated with $G$. sulfurreducens.

cysteine concentrations because of the formation of siderite and vivianite (data not shown). The particlesize distribution showed that themean particlesizes of residual solids in media containing 1 and $2 \mathrm{mM}$ cysteine were in the range of $0.11-$ 0.43 and $0.81-2.36 \mu \mathrm{m}$, respectively, with a mean of 0.18 and $1.49 \mu \mathrm{m}$, which is larger than that of ferrihydrite. This observation suggests that biogenicFe(II) minerals are formed.

Theinteraction of cysteineand iron(III) oxides is typically a one-electron-transfer reaction. The electron transfer from cysteineto $\mathrm{Fe}(\mathrm{III})$ in a nonenzymatic reaction, however, was 8- to 11-fold slower than that observed in the presence of G. sulfurreducens. Becausecysteine can provide the axial ligand for an iron(III) porphyrin in both cytochrome P450 and chloroperoxidaseand can be regenerated from cystine by $\mathrm{G}$. sulfurreducens (24), the comparison of reduction with other chelators and the effect of cystine on ferrihydrite reduction was further examined.

Dissolution of Ferrihydritein thePresence of Chelators. The influence of organic complexing agents on ferrihydrite reduction was examined to understand the effect of cysteine on Fe(III) reduction. Several potential ligands with carboxylic or amino functional groups including oxalic acid, glutamic acid, and alanine were selected. Also, nitrilotriacetic acid (NTA) and ethylenediaminetetraacetic acid (EDTA) were compared, which are the typical chelating agents that can significantly stimulate the microbial reduction of iron(III) oxides $(10,15,16)$

Little ferrihydrite was reduced in experiments that contained only complexing agents. Addition of $0.5 \mathrm{mM}$ NTA led to consistent enhancement of the rate and the extent of ferrihydrite reduction by $\mathrm{G}$. sulfurreducens (Figure 5A). The $\mathrm{Fe}(\mathrm{II})$ concentration increased rapidly in 2 days and then leveled off with time. Similar to NTA, the amendment with $0.5 \mathrm{mM}$ EDTA stimulated the microbial reduction of ferrihydrite significantly. A 5- and 6-fold increase in the final extent of ferrihydrite reduction was caused by $0.5 \mathrm{mM}$ NTA and $0.5 \mathrm{mM}$ EDTA, respectively, in relation to the nonchelated control.

Aqueous complexants have been shown to stimulate microbial iron(III) oxidereduction by solubilizing Fe(III) from the oxide surface $(8,10,15)$ or complexing biogenic Fe(II) (16), thereby enhancing the rate and the extent of iron(III) oxide reduction. Our results confirm that NTA and EDTA can stimulateferrihydritereduction bythesamemechanism. However, the solubilization effect with EDTA and NTA at different concentration was different. Increasing NTA concentration led to an increase in both total and dissolved Fe(II) concentration (Figure 5B). The speciation cal culation using MINTEQA2 program (32) showed that the enhancement of microbial reduction of ferrihydrite by NTA was mainly caused 
TABLE 1. Changes of Acetate and Fe(II) Concentrations and of Solid Minerals in G. sulfurreducens Cultures in the Presence of Cysteine at Various Concentrations after 22 Days of Incubation ${ }^{\mathrm{a}}$

item

final $\mathrm{pH}$

acetate consumed (mM)

cysteine

first-order rate constant $\left(\mathrm{h}^{-1}\right)$

initial rate $\left(\mathrm{mM} \mathrm{h}^{-1}\right)$

solid minerals

XRD analysis

color

suspended solid (SS) (mg/L)

biogenic iron oxide $\left(\mathrm{mg}\right.$ of siderite/L) ${ }^{c}$

particle size distribution

range $(\mathrm{nm})$

mean value $(\mathrm{nm})$

\begin{tabular}{llll}
\multicolumn{5}{c}{ cysteine-amended system (mM) } \\
\multicolumn{1}{c}{0} & \multicolumn{1}{c}{$\mathbf{1}$} & \multicolumn{1}{c}{$\mathbf{2}$} \\
6.97 & 7.08 & 7.12 & 7.34 \\
1.05 & 1.30 & 1.82 & 1.67 \\
& & 0.0186 & 0.0351 \\
$\mathrm{na}^{b}$ & 0.0089 & 0.211 & 0.228 \\
$\mathrm{na}$ & 0.221 & siderite, vivianite & siderite, vivianite \\
& & whitish gray & whitish gray \\
$\mathrm{Fe}(\mathrm{OH})_{3}$ & $\mathrm{Fe}(\mathrm{OH})_{3}$ & 1065 & 1388 \\
brown & dark brown & +369.3 & +864.2 \\
1203 & 950 & & \\
0 & -248 & $108-430$ & $10-2357$ \\
& & 179 & 1490
\end{tabular}

${ }^{a}$ The initial concentration of electron acceptor and donor was $10 \mathrm{mM}$ iron(III) oxides and $10 \mathrm{mM}$ acetate, respectively. ${ }^{b}$ Not available. ${ }^{c}$ The weight of biogenic iron(II) oxide was calculated as the difference of suspended solids between systems with and without cysteine and assumed that siderite was the major mineral solid after a 22-day incubation.
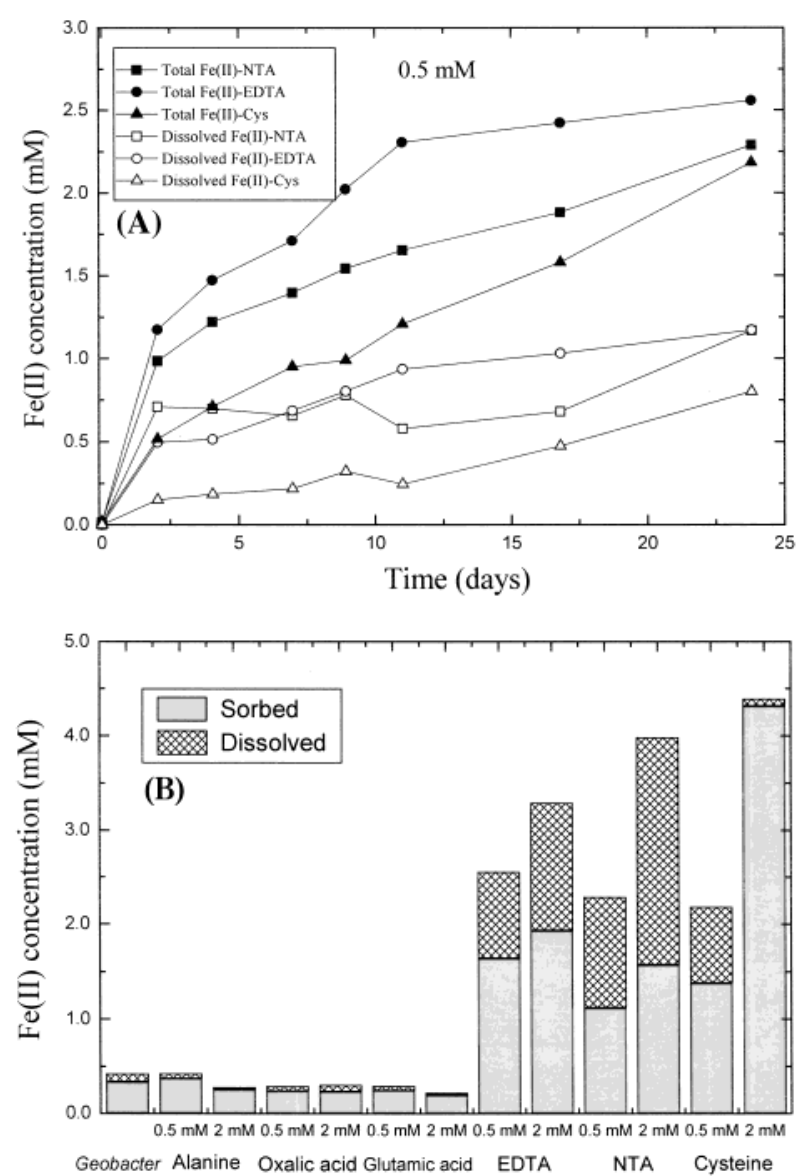

FIGURE 5. Microbial reduction of $10 \mathrm{mM}$ poorly crystalline iron(III) oxides by $G$. sulfurreducens amended with cysteine and different organic complexing agents. (A) total and dissolved Fe(II) production $w$ ith $0.5 \mathrm{mM}$ cysteine and complexing agents and $(B)$ concentrations of sorbed and dissolved Fe(II) in the presence of various concentrations of cysteine and complexing agents after 22 days of inc ubation.

by the formation of soluble Fe(II) complexes (Table 2). However, the final extent of ferrihydrite reduction was less enhanced if theEDTA concentration increased to $2 \mathrm{mM}$. The high stability constant of Fe(III)-EDTA reflects the fact that Fe(III)-EDTA is more difficult to reduce by G. sulfurreducens. Also, the higher stability constant of Fe(II)-EDTA (log $\left.\mathrm{K}_{\mathrm{Fe}(I I) E D T A}=15.98\right)$ than that of Fe(II)-NTA (log $\mathrm{K}_{\mathrm{Fe}(I I) N T A}=$
9.85) $(33,34)$ indicates a significant adsorption of the Fe(II)EDTA complex to the iron(III) oxide surfaces. Several metal EDTA complexes, including Fe(III) - and Fe(II)-EDTA complexes, have been shown to adsorb to the surface of iron minerals $(16,35,36)$. The high proportion of sorbed Fe(II) in the 2 mM EDTA-amended culture showed that EDTA was sorbed onto the surface of ferrihydrite and thus lowered the dissolved Fe(II) concentration. The low Fe(II)(aq) concentrations at high EDTA concentration calculated from MINTEQA 2 program support this conclusion (Table 2).

Amendments with oxalic acid, glutamic acid, or alanine decreased the reduction of iron(III) oxides. Thesecompounds contain amine or carboxylic functional groups and have stability constants for complex formation with Fe(II) similar to cysteine (Table 2). However, the total and dissolved Fe(II) produced in these cultures were lower than those in the nonchelated cultures. The extent of ferrihydrite reduction from $2 \%$ to $4 \%$ at $0.5 \mathrm{mM}$ to $1-2 \%$ at $2 \mathrm{mM}$. This decrease may be due to sorption of organic ligands to the surface of $\mathrm{Fe}(\mathrm{III})$, in competition with G. sulfurreducens. Results of adsorption experiments showed that the sorbed amounts of oxalic acid, glutamic acid, or alanine increased from 10 to $120 \mathrm{mg} / \mathrm{g}$ of $\mathrm{Fe}$ at $0.5 \mathrm{mM}$ to $80-230 \mathrm{mg} / \mathrm{g}$ of $\mathrm{Fe}$ at $2 \mathrm{mM}$, which supportsthis result. The Fe(II) speciation calculations indicate that no complex was formed in these three chelatoramended cultures, inferring that neither the amino nor the carboxylic group is the main functional group to stimulate Fe(III) reduction.

Different mechanisms for enhancing Fe(III) reduction in the presence of cysteine were observed. Thestability constant

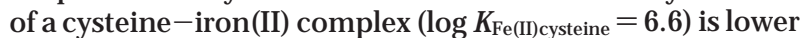
than those of EDTA-Fe and NTA-Fe. However, the total biogenic $\mathrm{Fe}(\mathrm{II})$ concentration with $0.5 \mathrm{mM}$ cysteine was similar to that in the NTA-amended assays. Increasing the cysteine concentration to $2 \mathrm{mM}$ also increased the total biogenic Fe(II) concentration. The dissolved Fe(II) increased with timeand then decreased when biogenic Fe(II) minerals wereformed (data not shown). Only a small proportion ( $<2 \%)$ of dissolved $\mathrm{Fe}(\mathrm{II})$ was detected after termination of the incubation. The calculated speciation results also showed that siderite and vivianite were the dominant Fe(II) species in cysteine-amended cultures (Table 2). This different distribution pattern from those in NTA- and EDTA-amended systems supports the hypothesis that solubilization is not the key mechanism in stimulation of Fe(III) reduction in cysteine-amended cultures.

Recycling of Cystine and Cysteine. If cysteine acts as an electron carrier, cystine, the oxidized form of cysteine, should 

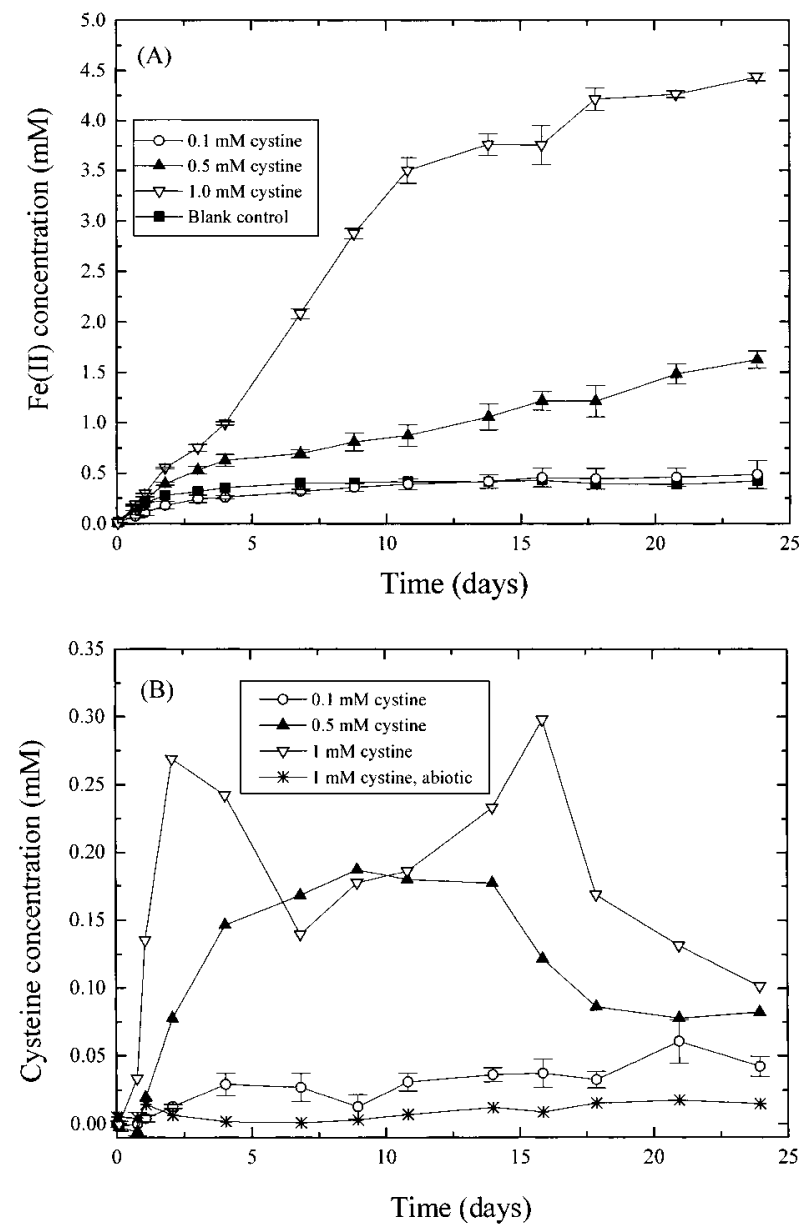

FIGURE 6. (A) Microbial reduction of $10 \mathrm{mM}$ poorly crystalline iron(III) oxides and (B) formation of cysteine in a G. sulfurreducens culture amended with various concentrations of cystine at initial $\mathrm{pH}$ of $7.1 \pm 0.1$.

be regenerated by Fe(III)-reducing bacteria, and the reduced form can transfer electrons to the surface of iron(III) oxide. Therefore, the reduction of ferrihydrite by $\mathrm{G}$. sulfurreducens at different concentrations of cystine was examined in this study. Although abiotic experiments and $0.1 \mathrm{mM}$ cystine had little effect on the rate of $\mathrm{Fe}(\mathrm{III})$ reduction, addition of cystine higher than $0.5 \mathrm{mM}$ stimulated the extent and rate of ferrihydrite reduction (Figure $6 \mathrm{~A}$ ). No obvious reduction of iron(III) oxides was observed within 1 day, presumably due to the necessary reduction of cystine to cysteine by G. sulfurreducens. Moreover, the extent of Fe(III) reduction in the cystine-amended culture was slightly lower than that in the cysteine-amended one (Figures $3 \mathrm{~A}$ and $6 \mathrm{~A}$ ), suggesting that cystine cannot be converted entirely to thecorresponding cysteine concentration.

The cysteine concentration increased slightly in a $0.1 \mathrm{mM}$ cystine-amended culture. Increasing the cystine concentration also increased the produced cysteine amounts (Figure $6 \mathrm{~B})$. The highest cysteine concentration of $0.18 \mathrm{mM}$ was observed after 9 days and then gradually decreased to 0.08 $\mathrm{mM}$ in the $0.5 \mathrm{mM}$ cystine-amended system. Two cysteine maxima at concentrations of 0.24 and $0.3 \mathrm{mM}$ at 2 and 16 days, respectively, were exhibited in the $1 \mathrm{mM}$ cystineamended system. It is noted that a nearly constant concentration of cyteine $(0.09-0.11 \mathrm{mM})$ was observed after 20 days of incubation. This value is similar to those in 0.5 and $2 \mathrm{mM}$ cysteine-amended cultures, reflecting that the formation of cysteine in the cystine-amended assays may probably be attributed to the electron shuttling process. 
The influence of cysteine stimulation on the extent and rate of iron(III) oxide reduction is not well understood. Because iron(III) oxides are highly insoluble at neutral $\mathrm{pH}$, iron-reducing bacteria must come into direct contact with the oxide surface for iron(III) oxide reduction when solution contains no chelating agent or electron shuttling compound. An outer membrane-bound protein is thus considered to be essential for microorganisms to couple Fe(III) reduction to growth. Various potential proteins, including outer and cytoplasmic membrane ferric reductase (37-39) and periplasmic cytochromes (40-42), have been suggested, but the definitive solution to this problem is still lacking. A recent study (24) shows that G. sulfurreducens can reduce cystine to cysteine in pure culture as well as in a coculture with W. succinogenes at rates of $6-22 \mathrm{nmol} \min ^{-1}(\mathrm{mg} \text { of protein })^{-1}$ coupled to the oxidation of acetate according to the following relationship:

$$
\begin{aligned}
& \mathrm{CH}_{3} \mathrm{COO}^{-}+\mathrm{H}^{+}+2 \mathrm{H}_{2} \mathrm{O}+4 \text { cystine } \rightarrow \\
& 2 \mathrm{CO}_{2}+8 \text { cysteine } \quad \Delta \mathrm{G}^{\circ}=-49 \mathrm{~kJ} / \mathrm{mol}
\end{aligned}
$$

With acetate as an electron donor, 4 mol of cystine will be reduced to $8 \mathrm{~mol}$ of cysteine. The produced cysteine would transfer electrons further to iron(III) oxide and bereoxidized to cystine. This process could provide more electrons and enhancetherateand extent of Fe(III) reduction significantly.

\section{Acknowledgments}

The authors thank Alexander von Humboldt-Stiftung for financial assistance to University Konstanz. This work was supported bya grant of the DeutscheForschungsgeminschaft, Bonn and by National Science Council, Taiwan, R.O.C. (NSC90-2621-Z007-002).

\section{Literature Cited}

(1) Stumm, W.; Sulzberger, B. Geochim. Cosmochim. Acta 1992, 56, 3233.

(2) Thamdrup, B. In Advanvcesin Microbial. Ecology, Vol. 16; Schink, B., Ed.; Kluwer Academic/ Plenum Publishers: New York, 2000; Chapter 2.

(3) Lovley, D. R.; Philliphs, E. J. P. Appl. Environ. Microbiol. 1987, 53, 1536.

(4) Yao, W.; Millero, F. L. Mar. Chem. 1996, 52, 1.

(5) Nowack, B.; Sigg, L. Geochim. Cosmochim. Acta 1997, 61, 951.

(6) Peiffer, S.; Dos Santos Afonso, M.; Wehrli, B.; Gaechter, R. Environ. Sci. Technol. 1992, 26, 2408.

(7) Larsen, O.; Postma, D. Geochim Cosmochim. Acta 2001, 65, 1367.

(8) Lovley, D. R. FEMS Microbiol. Rev. 1997, 20, 305.

(9) Straub, K. L.; Benz, M.; Schink, B. FEMS Microbiol. Ecol. 2001, 34, 181.

(10) Roden, E. E.; Urrutia, M. M. Environ. Sci. Technol. 1999, 33, 1847.

(11) Fredrickson, J. K.; Zachara, J. M.; Kennedy, D. W.; Dong, H.; Onstott, T. C.; Hinman, N. W.; Li, S. M. Geochim. Cosmochim. Acta 1998, 62, 3239.
(12) Lovley, D. R. Microbiol. Rev. 1991, 55, 259.

(13) Lovley, D. R.; Phillips, E. J. P. Appl. Environ. Microbiol. 1986, 52,752

(14) Roden, E. C.; Zachara, J. M. Environ. Sci. Technol. 1996, 30, 1618.

(15) Lovley, D. R.; Woodward, J. C. Chem. Geol. 1996, 132, 19.

(16) Urrutia, M.M.; Roden, E. E.; Zachara, J. M. Environ. Sci. Technol. 1999, 33, 4022.

(17) Lovley, D. R.; Coates, J. D.; Blunt-Harris, E. L.; Phillips, E. J. P.; Woodward, J. C. Nature, 1996, 382, 445.

(18) Scott, D. T.; McKnight, D. M.; Blunt-Harris, E. L.; Kolesar, S. E.; Lovley, D. R. Environ. Sci. Technol. 1998, 32, 2984.

(19) Newman, D. K.; Kolter, R. Nature 2000, 405, 94.

(20) Nevin, K. P.; Lovley, D. R. Environ. Sci. Technol. 2000, 34, 2472

(21) Sisley, M. J.; Jordan, R. B. Inorg. Chem. 1995, 34, 6015.

(22) Santana-Casiano, J., M.; González-Dávila, M.; Rodríguez, M. J.; Millero, F. J. Mar. Chem. 2000, 70, 211.

(23) Amirbahman, A.; Sigg, L.; von Gunten, U. J. Colloid. Interface Sci. 1997, 194, 194.

(24) Kaden, J.; Galushko, A. S.; Schink, B. Arch. Microbiol. 2002, submitted for publication.

(25) Widdel, F.; Bak, F. In The prokaryotes; Balows, A., Trüper, H. G., Dworkin, M., Harder, W., Schleifer, K.-H., Eds.; SpringerVerlag: New York, 1992; Chapter 183.

(26) Lovley, D. R.; Phillips, E. J. P. Appl. Environ. Microbiol. 1986 $51,683$.

(27) Stookey, L. L. Anal. Chem. 1970, 42, 779.

(28) Galushko, A. S.; Schink, B. Arch. Microbiol. 2000, 174, 314.

(29) Hogg, N. Free Radical Biol. Med. 1999, 27, 28.

(30) Buschmann, J.; Angst, W.; Schwarzenbach, R. P. Environ. Sci. Technol. 1999, 33, 1015.

(31) Caccavo, F., Jr.; Lonergan, D. J.; Lovley, D. R.; Davis, M.; Stolz, J. F.; Mclnerney, M. J. Appl. Environ. Microbiol. 1994, 60, 3752

(32) Allison, J. D.; Brown, D. S.; Novo-Gradac, K. J. MNTEQA2/ PRODEF2, A Geochemical Assessment Model for Environmental Systems; U.S. Environmental Protection Agency: Athens, GA, 1991.

(33) Smith, R. A.; Martell, A. E. NIST Critically selected Stability Constants of metal complexes database; U.S. Department Commerce: Gaithersburg, MD, 1997.

(34) Morel, F. M. M.; Hering, J. G. Principles and Applications of Aquatic Chemistry; Wiley: New York, 1993; p 332.

(35) Nowack, B.; Lützenkirchen, J.; Behra, P.; Sigg, L. Environ. Sci. Technol. 1996, 30, 2397.

(36) Butler, E.; Hayes, K. F. Environ. Sci. Technol. 1998, 32, 1276.

(37) Gaspard, S.; Vazquez, F.; Holliger, C. Appl. Environ. Microbiol. 1998, 64, 3188.

(38) Magnuson, T. S.; Hodges-Myerson, A. L.; Lovley, D. R. FEMS Microbiol. Lett. 2000, 185, 205.

(39) Magnuson, T. S.; Isoyama, N.; Hodges-Myerson, A. L.; Davidson, G.; Maroney, M. J.; Geesey, G. G.; Lovley, D. R. Biochem. J. 2001, 359, 147.

(40) Seeliger, S.; Cord-Ruwisch, R.; Schink, B. J. Bacteriol. 1998, 180, 3686.

(41) Myers, C. R.; Myers, J. M. J. Bacteriol. 1992, 174, 3429.

(42) Myers, C. R.; Myers, J. M. J. Bacteriol. Biochim. Biophys. Acta 1997, 1326, 307. 